\title{
Collecting-Duct Carcinoma of the Kidney with Prominent Signet Ring Cell Features
}

\author{
Maomi Li, M.D., Ph.D., Magalis A. Vuolo, M.D., Karen M. Weidenheim, M.D., Lloyd S. Minsky, M.D. \\ Departments of Pathology and Urology, Albert Einstein College of Medicine/Montefiore Medical Center, \\ Bronx, NY
}

We report a case in a 74 -year-old woman of collecting-duct carcinoma of the kidney with prominent signet ring cell features. Grossly, the tumor measured $5.5 \mathrm{~cm}$ in greatest dimension, occupied the entire upper pole of the kidney, and was well circumscribed. Microscopically, it displayed a predominant tubulopapillary pattern of growth with a hyalinizing stroma. The tumor tubules were lined by a single layer of cells with large, pleomorphic nuclei, some of which had a hobnail appearance. Large intracytoplasmic vacuoles with compression of nuclei (signet ring cells) were present throughout the tumor. Alcian blue, mucicarmine, and periodic acid-Schiff stains failed to identify intracellular mucin or glycogen in the signet ring cells. Enlarged cells with intracytoplasmic vacuoles were also noted in the adjacent collecting ducts. The tumor cells were immunohistochemically positive for cytokeratin including cytokeratin 7 , CAM 5.2, AE1/3, and 34ßE12, vimentin, peanut lectin agglutinin, and Ulex europaeus agglutinin. Electron microscopy revealed that the intracytoplasmic vacuoles were due to intracellular edema. To the best of our knowledge, this is the first reported case of renal collecting-duct carcinoma with prominent signet ring cell features.

KEY WORDS: Collecting-duct carcinoma, Intracellular edema, Kidney, Signet ring cell.

Mod Pathol 2001;14(6):623-628

Copyright $\odot 2001$ by The United States and Canadian Academy of Pathology, Inc.

VOL. 14, NO. 6, P. 623, 2001 Printed in the U.S.A.

Date of acceptance: February 14, 2001.

Address reprint requests to: Maomi Li, M.D., Ph.D., Department of Pathology, The Jack Weiler Hospital of Albert Einstein College of Medicine, 1825 Eastchester Road, Room 338, Bronx, NY 10461; e-mail: maomili@pol.net; fax: 718-904-2355.
Signet ring cells are morphologically characterized by the presence of intracytoplasmic vacuoles, which push the nuclei to the cellular borders. Signet ring cells have been described in many types of tumors, most of which are adenocarcinomas. They are most commonly seen in the stomach but are also present in many other organs, including colon, appendix, breast, lung, urinary bladder, pancreas, and gallbladder (1). The signet ring morphology in these tumors is due to the accumulation of intracytoplasmic mucin, resulting in nuclear compression. In addition to signet ring adenocarcinomas, signet ring cells have also been described in many other neoplasms, such as adenoma and carcinoma of the thyroid, lymphoma, cutaneous neoplasms, gastrointestinal stromal tumor, and stromal tumor of the ovary (2-6). Signet ring cell changes in the latter tumor types are usually due to intracellular accumulation of various materials other than mucin.

Renal cell carcinomas include a group of histologically heterogeneous tumors. Currently, renal cell carcinoma is classified into clear-cell (conventional), papillary (chromophil), chromophobe, collecting duct (including medullary), and unclassified types (7). Although various morphological features are seen in different types of renal cell carcinoma, signet ring renal cell carcinoma has not been described. We report here a case of collecting-duct carcinoma (CDC) of the kidney with prominent signet ring cell features.

\section{CASE REPORT}

The patient was a 74-year-old African American woman who had a history of abdominal aortic aneurysm. During a computed tomographic (CT) work-up for the aneurysm, she was found to have a mass in the upper pole of her right kidney. There was no evidence of renal vein invasion, extrarenal involvement, or lymph node or distant metastasis. The patient did not complain of hematuria or flank pain. A diagnosis of renal cell carcinoma was made based on the CT findings. 
She underwent radical right nephrectomy. The kidney, together with the Gerota's fascia and perinephric fat, was easily removed without evidence of adhesion. Postoperative follow-up (10 months), including CT scan, revealed no evidence of recurrent or metastatic disease. The patient did not have a history of sickle cell trait.

\section{MATERIALS AND METHODS}

Tissue was fixed in $10 \%$ neutral buffered formalin, embedded in paraffin, and stained with hematoxylin and eosin, periodic acid-Schiff (periodic acid-Schiff), Alcian blue, and mucicarmine. Immunohistochemical studies were performed on formalin-fixed, paraffin-embedded blocks with the primary antibodies and lectins listed in Table 1. Immunoreactivity was detected using DAKO LSAB-2 kit detection system (DAKO, Carpinteria, CA) according to the manufacturer's recommended procedure. For electron microscopy, tissue was first fixed in formalin, then in glutaraldehyde, postfixed in osmium tetroxide, dehydrated, and embedded in epoxy resin. Thin sections stained with uranyl acetate and lead citrate were examined under transmission electron microscope using a JEOL 100 S electron microscope.

\section{PATHOLOGICAL FINDINGS}

Gross examination revealed a well-circumscribed tumor measuring $5.5 \times 5.0 \times 4.5 \mathrm{~cm}$ and occupying almost the entire upper pole of the kidney. The cut surface of the tumor was tan to light yellow with areas of geographic necrosis and hemorrhage (Fig. 1). The tumor was confined to the kidney and did not invade the renal vessels or the pelvis. The renal pelvis was dilated, and the non-neoplastic kidney adjacent to the tumor showed focal necrosis in the medulla. Microscopically, the tumor was well demarcated from the surrounding kidney and partially surrounded by dense, fibrous tissue. It displayed predominantly a tubulopapillary pattern of growth (Fig. 2A). The tubules were surrounded by a thick layer of basement membrane and lined by a single layer of cuboidal to low-columnar cells. Pale luminal secretion was infrequently present. The nuclei were intermediate to large in size and varied from round to oval with moderate pleomorphism and prominent nucleoli. The most prominent feature was the presence of variably sized intracytoplasmic vacuoles, some of which compressed the nuclei, resulting in a signet ring appearance in many tumor cells (Fig. 2B). The amount of cytoplasm in the cells without cytoplasmic vacuoles was scanty to moderate, and some cells lining the tubules displayed a hobnail appearance. A minor solid pattern (about 10\% of the tumor) was present in several areas and associated with slightly spindled tumor cells and pleomorphic nuclei (Fuhrman Grade 4; Fig. 2C). Mitoses were only infrequently seen. Areas of tumor necrosis and aggregates of foamy histiocytes, lymphocytes, and plasma cells were present throughout the entire tumor. Although the tumor had a hyalinized stroma, a marked desmoplastic reaction was not seen. In the non-neoplastic kidney, tubular cells with slightly enlarged nuclei and intracytoplasmic vacuoles similar to those seen in the tumor cells were noted in some collecting ducts in the renal papillae, but not in other locations in the kidney (Fig. 3).

Mucicarmine and Alcian blue stains revealed occasional intraluminal mucin. However, the cytoplasmic vacuoles were not stained with mucicarmine, Alcian blue, or periodic acid-Schiff, indicating that they contained neither mucin nor glycogen (Fig. 2D). Thick basement membrane surrounding tumor tubules was highlighted on periodic acid-Schiff stain. Immunohistochemical studies revealed that the tumor cells were strongly positive for cytokeratins, including cytokeratins 7, CAM 5.2, AE $1 / 3$, and 34 $\beta \mathrm{E} 12$, vimentin, peanut lectin agglutinin (PNA), and Ulex europaeus agglutinin 1 (UEA-1) (Figure 4). They also reacted focally with Leu M1 but were completely negative for cytokeratin 20 , epithelial membrane antigen, and carcinoembryonic antigen.

TABLE 1. Lists of Antibodies and Lectins Used for Immunohistochemical Staining

\begin{tabular}{|c|c|c|c|}
\hline Antibody/Lectin ${ }^{a}$ & Source & Dilution & Pretreatment \\
\hline $\mathrm{AE} 1 / \mathrm{AE} 3(\mathrm{~m})$ & Boehringer/Mannheim & $1: 100$ & protease digestion \\
\hline CAM $5.2(\mathrm{~m})$ & Boehringer/Mannheim & prediluted & protease digestion \\
\hline Cytokeratin 7 (m) & DAKO & $1: 50$ & steamer heat at $\mathrm{pH} 6.0$ \\
\hline Cytokeratin 20 (m) & DAKO & $1: 50$ & protease digestion \\
\hline Cytokeratin $34 \beta \mathrm{E} 12$ & DAKO & $1: 100$ & steamer heat at $\mathrm{pH} 6.0$ \\
\hline Carcinoembryonic antigen (m) & DAKO & $1: 200$ & steamer heat at $\mathrm{pH} 6.0$ \\
\hline Epithelial membrane antigen (p) & DAKO & $1: 100$ & protease digestion \\
\hline Leu M1 (m) & Cell Marque & $1: 50$ & steamer heat at $\mathrm{pH} 6.0$ \\
\hline Peanut lectin agglutinin & Vector Laboratories & $10 \mu \mathrm{m} / \mathrm{mL}$ & none \\
\hline Ulex europaeus agglutinin 1 & Cell Marque & $1: 100$ & steamer heat at $\mathrm{pH} 6.0$ \\
\hline Vimentin (m) & Immunotech & $1: 800$ & protease digestion \\
\hline
\end{tabular}

${ }^{a} \mathrm{~m}$, mouse monoclonal antibodies; p, rabbit polyclonal antibodies. 
Ultrastructurally, the tumor cells contained round to oval nuclei with slightly irregular nuclear membranes. Organelles were relatively scanty. Dilated mitochondria, rough endoplasmic reticulum, lysosomes, and occasional small fat droplets were present. The most prominent feature was the presence of non-membrane-bounded intracytoplasmic empty spaces, in which organelles were very sparse (Fig. 5). Mucinogens, glycogen, or large fat droplets were not observed. Small nests of tumor cells were delineated by a thick basal lamina.

\section{DISCUSSION}

Collecting duct carcinoma of the kidney is histologically characterized by tubulopapillary pattern of growth, marked desmoplasia, inflammatory infiltrate, high-grade cytological features with hobnail nuclei, and mucin production $(8,9)$. This histologically distinct tumor is very rare, with less than 100 cases reported in the literature, and accounts for approximately $1 \%$ of all malignant renal epithelial tumors (8-17). Origin from the collecting duct is suggested by its usual medullary location; its immunoreactivity with UEA-1, PNA, and high molecular weight cytokeratin (34 $\beta \mathrm{E} 12)$ similar to collecting-duct cells; and dysplastic changes frequently seen in adjacent collecting ducts (8-11). Microsatellite allelotyping studies have revealed that chromosomal imbalances associated with CDC are different from those found in other types of renal cell carcinoma (18-21).

Most CDCs are clinically aggressive, frequently resulting in death $(8,9)$. However, a group of lowgrade CDC with favorable outcome has also been proposed (16), suggesting a morphological as well as biological spectrum of the tumor $(16,22)$. In 1995, Davis et al. (23) described another renal neoplasm termed renal medullary carcinoma, which almost exclusively occurred in young patients with sickle cell trait or other hemoglobin disorders and was associated with an extremely aggressive clinical behavior. This latter tumor shares many histological features with CDC, such as inflammatory desmoplastic stroma, mucin production, and immunohistochemical reactivity with $34 \beta E 12$, PNA, and UEA-1. Many authors, therefore, consider renal medullary carcinoma to be a subtype of CDC with distinct clinical and genetic settings (7-9).

We classify our current case as a CDC based on the following features: predominantly tubulopapillary pattern of growth, hobnail cells, presence of occasional luminal mucin, positive reactivity with cytokeratin $34 \beta \mathrm{E} 12$, PAN, and UEA-1, and similar cytological changes in the adjacent collecting ducts.

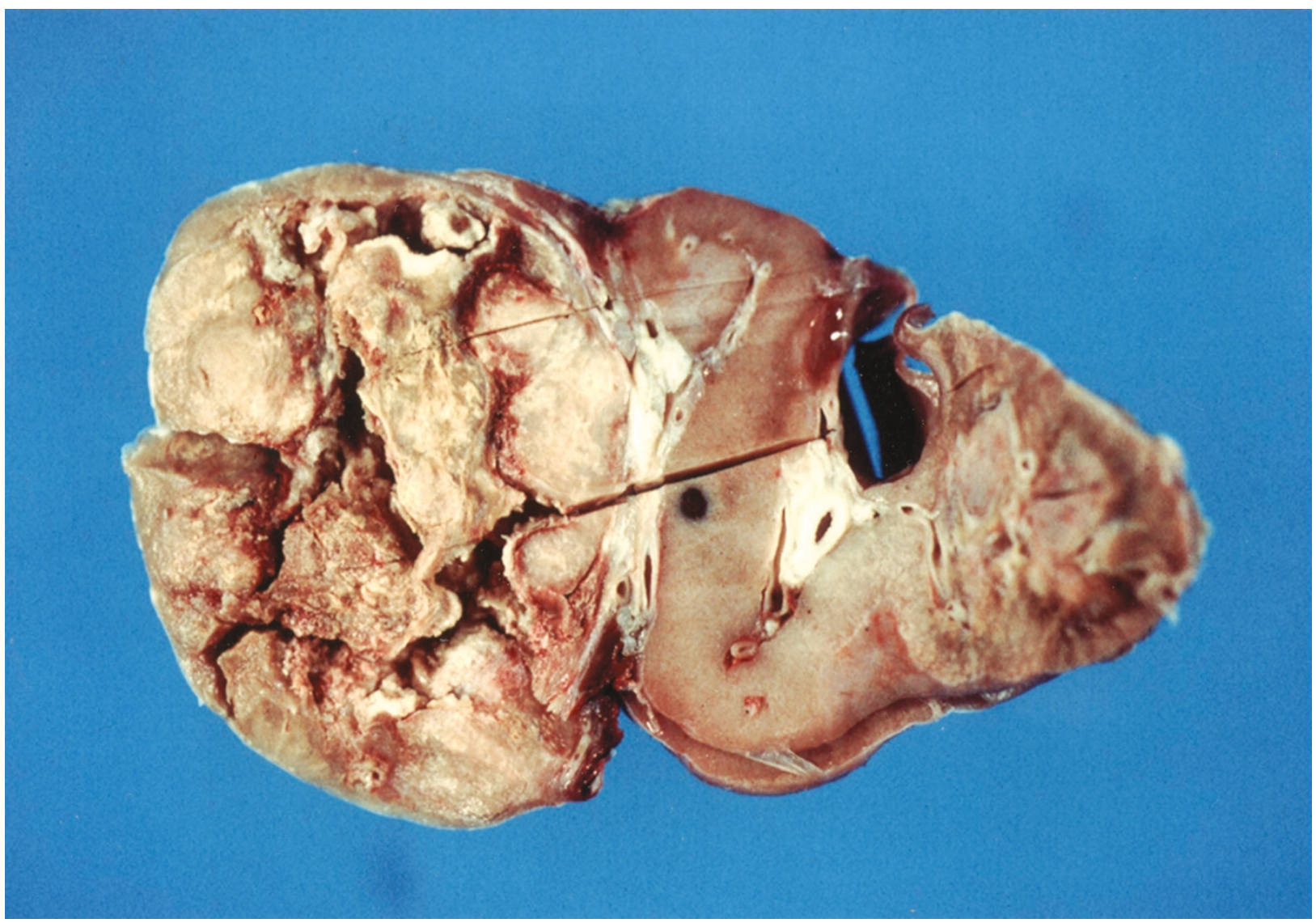

FIGURE 1. The renal tumor measures $5.5 \mathrm{~cm}$ and occupies the entire upper pole of the kidney. The cut surface is tan to light yellow with areas of geographic necrosis. 

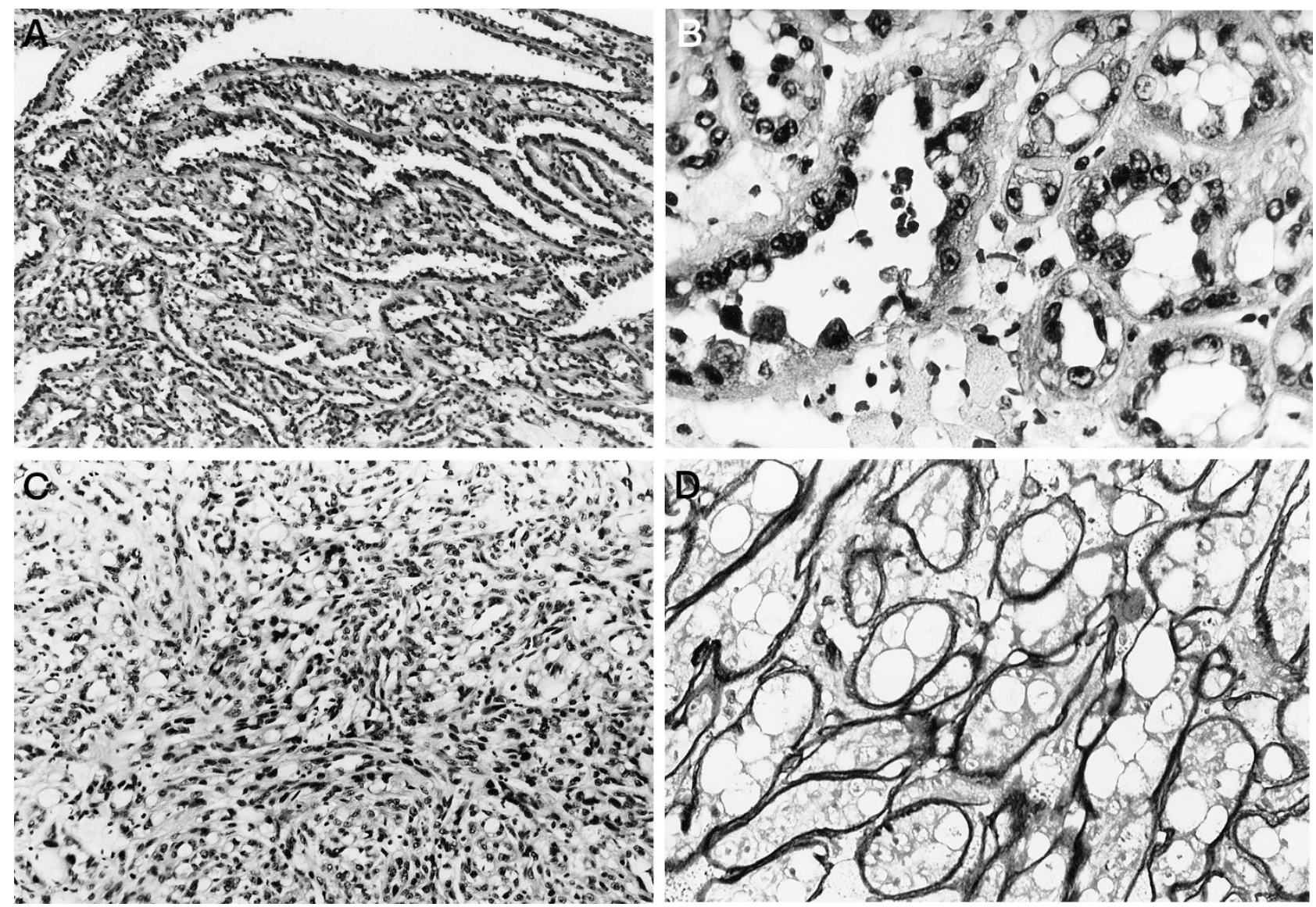

FIGURE 2. A, low-power view of a tubulopapillary pattern. B, at high power, the tubules are lined by a single layer of tumor cells with large nuclei, some of which have prominent nucleoli. Signet ring cells and hobnail nuclei are easily appreciated. C, a solid area consisting of spindle cells, many of which also contain intracytoplasmic vacuoles. D, the intracytoplasmic vacuoles fail to react with periodic acid-Schiff. Note the thick basement membrane highlighted by periodic acid-Schiff staining.

However, our tumor lacked a marked desmoplastic reaction and an infiltrating border, which may account for its relative less aggressive behavior (pT1 tumor without evidence of metastasis). Its highgrade cytological features with a lack of infiltrating nature place this tumor in the middle of the histological spectrum of CDC. The presence of a dilated renal pelvis and focal necrosis of the nonneoplastic kidney was probably the results of compression caused by the tumor. The patient's age, the absence of sickle cell trait, and the localized nature of the disease were strong evidence against a diagnosis of renal medullary carcinoma. Although our tumor displayed some overlapping architectural features with an unusual group of renal cell carcinoma composed of low-grade small cuboidal cells arranged in tubular, solid, and spindled arrays, recently reported by Srigley et al. (24) in an abstract form, the preponderance of tubulopapillary pattern, the high nuclear grade, and the positive immunoreactivity with $34 \beta E 12$, PNA, and UEA-1 distinguish our case from the latter.

Although mucin production, either intraluminal or intracellular, has been reported in most CDCs (8, 9 ), to the best of our knowledge, signet ring cells have not been described in renal cell carcinoma, including CDC. Davis et al. (23) described a microcystic pattern in renal medullary carcinoma, but signet ring cells were not mentioned. To our surprise, the signet ring cells did not contain mucin, as evidenced by the negative staining for mucicarmine, Alcian blue, and periodic acid-Schiff and by

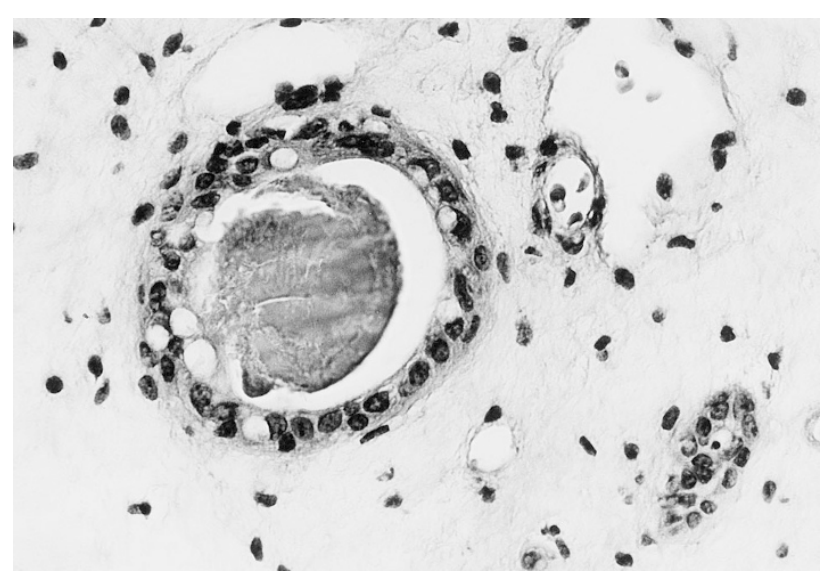

FIGURE 3. Slightly enlarged cells, some of which contain cytoplasmic vacuoles, line a collecting duct from an adjacent renal papilla. 


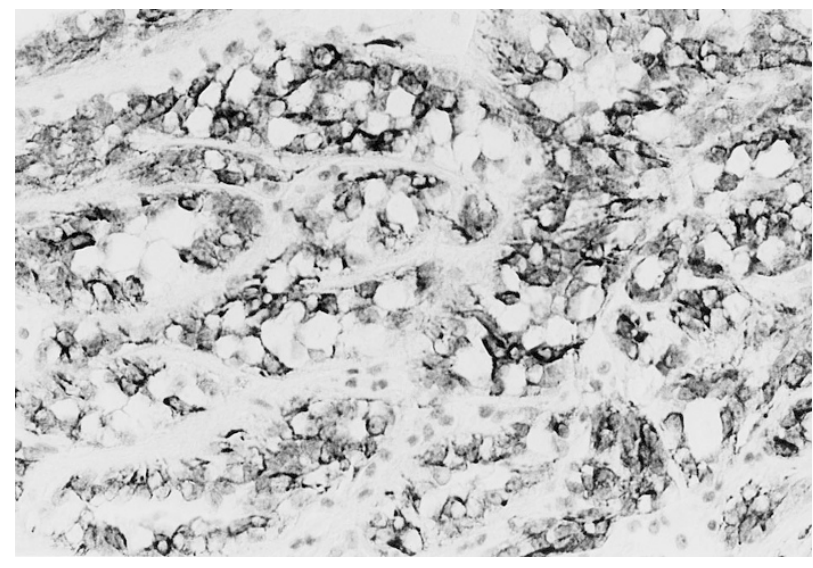

FIGURE 4. The tumor cells are immunohistochemically positive for high molecular weight cytokeratin $34 \beta \mathrm{E} 12$.

the absence of mucinogens ultrastructurally. No significant number of fat droplets or glycogen granules were detected in electron microscopy to account for the empty cytoplasmic vacuoles. The pathogenesis of these intracytoplasmic vacuoles is not entirely clear. One possible cause is artifact. Signet ring-like changes attributable to biopsy and formalin fixation have been found in lymphocytes and smooth muscle cells in transurethral resection specimens of the prostate, gastric lymphoma, and gastrointestinal stromal tumor (25-27). We cannot completely rule out the possibility of retraction artifact in our case because tissue sections taken for both histological and ultrastructural studies were formalin fixed. The fact that similar change was not present in the non-neoplastic cells, including the benign tubular epithelium, and that signet ring morphology has not been observed by other authors in the same type of tumor suggests that this is a very rare phenomenon. We favor an interpretation that the intracytoplasmic empty spaces re-

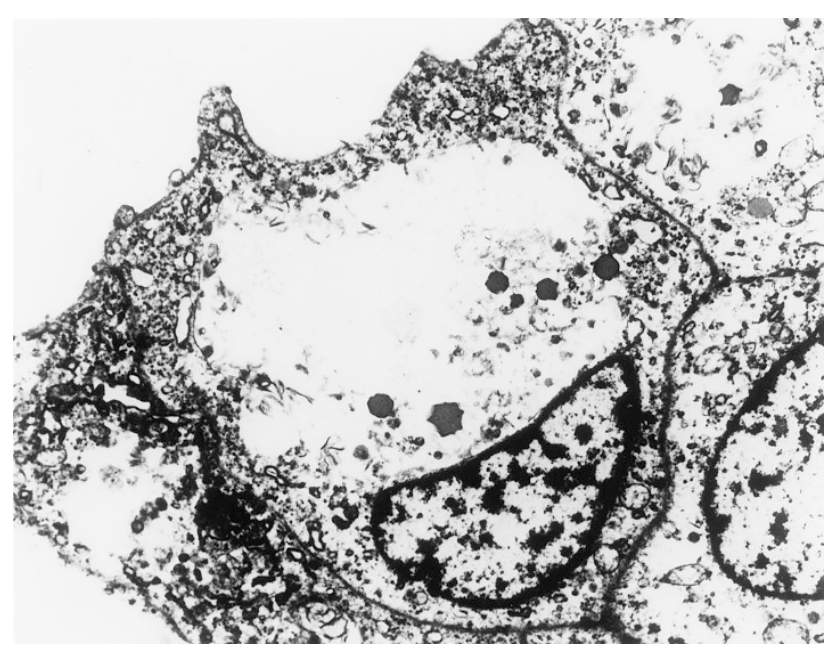

FIGURE 5. Electron micrography: the cytoplasm of a tumor cell is edematous with sparse organelles $(6000 \times)$. vealed by light and electron microscopy are probably the results of intracellular edema and degeneration, which displaced most of the organelles. Although classic signet ring cells are characterized by intracytoplasmic accumulation of mucin, other materials, including edema, have been reported to be responsible for signet ring cell formation in some neoplasms (4-6). Recently, Koller et al. also reported two cases of renal oncocytoma with prominent intracytoplasmic vacuoles due to the presence of degenerative mitochondria (28). The presence of thick basement membranes in our current case further suggests that the tumor cells underwent some degenerative processes.

\section{REFERENCES}

1. Rosai J. Ackerman's surgical pathology, 8th ed. St. Louis, MO: Mosby; 1996.

2. Carcangiu ML, Sibley RK, Rosai J. Clear cell change in primary thyroid tumors. A study of 38 cases. Am J Surg Pathol 1985;9:705-22.

3. Hanna W, Kahn HJ, From L. Signet ring lymphoma of the skin: ultrastructural and immunohistochemical features. J Am Acad Dermatol 1986;14:344-50.

4. Bastian BC, Kutzner H, Yen TS, Le Boit PE. Signet-ring cell formation in cutaneous neoplasms. J Am Acad Dermatol 1999;41:606-13.

5. Suster S, Fletcher CD. Gastrointestinal stromal tumors with prominent signet-ring cell features. Mod Pathol 1996;9:60913.

6. Dickersin GR, Young RH, Scully RE. Signet-ring stromal and related tumors of the ovary. Ultrastruct Pathol 1995;19:40119.

7. Kovacs G, Akhtar M, Beckwith BJ, Bugert P, Cooper CS, Delahunt B, et al. The Heidelberg classification of renal cell tumors. J Pathol 1997;183:131-3.

8. Srigley JR, Eble JN. Collecting duct carcinoma of kidney. Semin Diagn Pathol 1998;15:54-67.

9. Amin MB, Varma MD, Tickoo SK, Ro JY. Collecting duct carcinoma of the kidney. Adv Anat Pathol 1997;4:85-94.

10. Fleming S, Lewi HJ. Collecting duct carcinoma of the kidney. Histopathology 1986;10:1131-41.

11. Rumpelt HJ, Storkel S, Moll R, Scharfe T, Thoenes W. Bellini duct carcinoma: further evidence for this rare variant of renal cell carcinoma. Histopathology 1991;18:115-22.

12. Kennedy SM, Merino MJ, Linehan WM, Roberts JR, Robertson CN, Neumann RD. Collecting duct carcinoma of the kidney. Hum Pathol 1990;21:449-56.

13. Baer SC, Ro JY, Ordonez NG, Maiese RL, Loose JH, Grignon DG, et al. Sarcomatoid collecting duct carcinoma: a clinicopathologic and immunohistochemical study of five cases. Hum Pathol 1993;24:1017-22.

14. Caraway NP, Wojcik EM, Katz RL, Ro JY, Ordonez NG. Cytological findings of collecting duct carcinoma of the kidney. Diagn Cytopathol 1995;13:304-9.

15. Dimopoulos MA, Logothetis CJ, Markowitz A, Sella A, Amato R, Ro J. Collecting duct carcinoma of the kidney. Br J Urol 1993;71:388-91.

16. MacLennan GT, Farrow GM, Bostwick DG. Low-grade collecting duct carcinoma of the kidney: report of 13 cases of low-grade mucinous tubulocystic renal carcinoma of possible collecting duct origin. Urology 1997;50:679-84.

17. Matz LR, Latham BI, Fabian VA, Vivian JB. Collecting duct carcinoma of the kidney: a report of three cases and review of the literature. Pathology 1997;29:354-9. 
18. Fogt F, Zhuang Z, Linehan WM, Merino MJ. Collecting duct carcinomas of the kidney: a comparative loss of heterozygosity study with clear cell renal cell carcinoma. Oncol Rep 1998;5:923-6.

19. Polascik TJ, Cairns P, Epstein JI, Fuzesi L, Ro JY, Marshall FF, et al. Distal nephron renal tumors: microsatellite allelotype. Cancer Res 1996;56:1892-5.

20. Shoenberg M, Cairns P, Brooks JD, Marshall FF, Epstein JI, Isaacs WB, et al. Frequent loss of chromosome arm $8 \mathrm{p}$ and $13 q$ in collecting duct carcinoma (CDC) of the kidney. Genes Chromosom Cancer 1995;12:76-80.

21. Steiner G, Cairns P, Polascik TJ, Marshall FF, Epstein JI, Sidransky D, et al. High-density mapping of chromosomal arm 1q in renal collecting duct carcinoma: region of minimal deletion at 1q32.1-32.2. Cancer Res 1996;56:5044-6.

22. Murphy W, Beckwith J, Farrow G. Tumors of the kidney, bladder and related urinary structures. In: Rosai J, editor. Atlas of tumor pathology, 3rd series, Fascicle 11. Washington, D.C.: Armed Forces Institute of Pathology; 1994.
23. Davis CJ Jr, Mostofi FK, Sesterhenn IA. Renal medullary carcinoma: the seventh sickle cell nephropathy. Am J Surg Pathol 1995;19:1-11.

24. Srigley JR, Eble JN, Grignon DJ, Hartwick RWJ. Unusual renal cell carcinoma (RCC) with prominent spindle cell change possibly related to the loop of Henle [abstract]. Mod Pathol 1999;12:107A.

25. Alguacil-Garcia A. Artifactual changes mimicking signet ring cell carcinoma in transurethral prostatectomy specimens. Am J Surg Pathol 1986;10:795-800.

26. Arista-Nasr J, Romero-Lagarza P, Pichardo-Bahena R. Artifactual signet-ring-like cells in endoscopic biopsy of gastric lymphoma. Arch Pathol Lab Med 1997;121:623-5.

27. Ferrer MD, Lloreta J, Corominas JM, Ribalta T, Iglesias M, Serrano S. Signet ring epithelioid stromal tumor of the small intestine. Ultrastruct Pathol 1999;23:45-50.

28. Koller A, Kain R, Haitel A, Mazal PR, Asboth F, Susani M. Renal oncocytoma with prominent intracytoplasmic vacuoles of mitochondrial origin. Histopathology 2000;37:264-8. 